\title{
LA INCIDENCIA DE LA HELADA DE 1956 EN EL OLIVAR DE NAVATA (ALT EMPORDÀ, GIRONA)
}

\author{
Sandra Ricart Casadevall \\ Anna Ribas Palom \\ Departamento de Geografía \\ Universitat de Girona
}

\section{RESUMEN}

En la comarca del Alt Empordà (Girona), el olivar ha configurado históricamente un paisaje de alto valor económico, cultural y ambiental si bien desde mediados del siglo XX se encuentra en fuerte regresión. Uno de los municipios situados en el límite de la plana altoampurdanesa que mejor ejemplifican este proceso de abandono y casi desaparición del olivar es Navata. Este artículo analiza los cambios experimentados en el olivar de este municipio en el periodo 1957-2004 a través tanto de la elaboración de una cartografía de usos y cubiertas del suelo a escala de detalle como del análisis de fuentes estadísticas y orales, ejercicio que pone de relieve la pérdida del $90 \%$ del olivar existente a mediados del siglo pasado. La helada de febrero de 1956 fue uno de los principales causantes, pero no el único. Sin embargo, tanto la importancia del olivar como elemento identitario y de conservación de la biodiversidad como el carácter diferenciador del aceite que se obtiene a partir de variedades propias de la zona (especialmente la argudell), justifican la necesidad de impulsar políticas que ayuden a su recuperación.

Palabras clave: paisaje de olivar, helada de 1956, estructura productiva agraria, Política Agraria Común, Navata, Alt Empordà.

\begin{abstract}
In the region of Alt Empordà (Girona), olive groves historically shaped a landscape of high economic value, cultural and environmental although since mid-twentieth century is in sharp decline. One of the municipalities located on the edge of the plana altoampurdanesa that best exemplify this process of abandonment and near disappearance of that crop is Navata. This article analyzes the changes in the olive grove of this municipality in the period 1957-2004, both through the development of mapping land use and land cover level of detail as the analysis of data sources and oral exercise that makes emphasizes the loss of $90 \%$ of the existing olive grove in the middle of last century. The frost of February of
\end{abstract}


1956 was one of the main causes, but not unique. However, both the importance of the olive groves as an identity and conservation of biodiversity as the differential nature of the oil obtained from varieties natives to the area (especially argudell), justify the need to promote policies that will help your recovery.

Key words: olive groves landscape, 1956 frost, agricultural production structure, Common Agricultural Policy, Navata, Alt Empordà.

\section{Introducción}

El olivo es el árbol emblemático de la región mediterránea. La historia del olivo y del aceite es la historia de la agricultura mediterránea (Bolens, 1996; Fortuny, 2002). Al igual que sucede en otros sistemas agrarios extensivos, son muchos y complejos los bienes y servicios de tipo económico, social y ambiental que configuran la multifuncionalidad del olivar en el ámbito mediterráneo (Fleskens, 2009). Desde el punto de vista económico es uno de los bienes comerciales más relevantes (aunque sólo representa el $4 \%$ de la cuota mundial de aceites vegetales) y juega un papel destacado en el desarrollo rural como fuente de ingresos y generador de ocupación en zonas de secano. Desde el punto de vista social y cultural el olivar ha dejado su huella en la fisonomía de los espacios agrarios contribuyendo a la creación del paisaje tradicional del secano y ejerciendo de símbolo identitario de la mediterraneidad. Por último, desde la perspectiva ambiental, el ecosistema de olivar es muy estable en comparación con otros ecosistemas agrícolas, especialmente por la baja exigencia de recursos empleados en su producción; cabe añadir su contribución al mantenimiento del suelo frente a la erosión, el reducido número de plagas que debe soportar y la abundante avifauna que acoge (Anta, 2005).

El hábitat del olivo se concentra entre las latitudes $30^{\circ}$ y $45^{\circ}$ tanto en el hemisferio norte como en el sur, en regiones climáticas de tipo mediterráneo, caracterizadas por un verano seco y caluroso y un invierno relativamente suave (Barranco, 2004; Civantos, 1995; Maté, 2004; Sabaté y Colom, 1994). Los países líderes en producción de aceite de oliva son, por este orden, España, Italia y Grecia, seguidos a una distancia considerable por Turquía, Siria, Túnez, Marruecos, Egipto, Argelia y Portugal, todos ellos ubicados en la cuenca mediterránea, donde se produce el 95\% del total mundial (FAOSTAT, 2008; IOC, 2009). Según el Anuario de Estadística 2008 del Ministerio de Medio Ambiente y Medio Rural y Marino (MARM, 2008), España, con una superficie de 2,47 millones de hectáreas de olivar, es el primer productor mundial de aceite de oliva con 6,14 millones de toneladas anuales, lo que supone el 37,72\% de la producción total de la cuenca mediterránea y el 35,57\% de la producción mundial. Esta misma fuente estadística destaca Andalucía como la región líder en producción, aglutinando el 82,6\% de la producción anual estatal, con las provincias de Jaén y Córdoba como máximas exponentes $(36,47 \%$ y $20,72 \%$ de la producción anual total, respectivamente). Le siguen Castilla-La Mancha con el 6,4\% de la producción estatal, donde despuntan las provincias de Toledo y Ciudad Real (3,2\% y 1,8\%, respectivamente); Extremadura, con el $5,1 \%$ de la producción, centrada en la provincia de Badajoz $(4,1 \%$ del total estatal); y Cataluña, que aporta el 1,7\% de la producción, resaltando el papel de las provincias de Tarragona y Lleida ( $1,2 \%$ y $0,004 \%$ respectivamente).

En Cataluña el olivar ocupaba en el año 2007 una superficie de 122.889 hectáreas, representando un 4,9\% de la superficie total del sector en España, el 1,51\% a nivel europeo y el 1,43\% a escala mundial (IOC, 2009). La producción de aceite de oliva en la región catalana para el mismo año se situó en las 104.990 toneladas (DAR, 2008). Geográficamente el olivar catalán se concentra en las provincias de Lleida (comarcas del Pallars Jussà y de 
la Noguera) y especialmente de Tarragona (en las comarcas de Les Garrigues, la Ribera d'Ebre, el Baix Ebre, el Baix Camp y el Montsià). A mayor distancia, en el nordeste de la provincia de Girona, destaca la comarca del Alt Empordà, con una superficie destinada al olivar cifrada en 2.243 hectáreas para el año 2007 (el 1,84\% de la superficie de olivar en Cataluña) y una producción para el mismo año de 2.403 toneladas (el 2,03\% de la producción catalana), con las variedades argudell, corivell y arbequina como las más representativas del sector ${ }^{1}$ (Mercacei, 1998).

El objetivo de este artículo es documentar y analizar, a través de la cartografía de usos y cubiertas del suelo, la interpretación de las fuentes estadísticas disponibles y la realización de entrevistas a los agricultores del sector olivarero, los cambios experimentados en el olivar en el municipio de Navata (Alt Empordà) a partir de mediados del siglo XX y hasta la actualidad. Nos interesa sobre todo precisar la incidencia real que tuvo uno de los factores de cambio que invariablemente se han apuntado como determinantes para explicar el declive del olivar en la comarca: el episodio climático de la helada de febrero de 1956. La hipótesis de partida sostiene que a pesar de los elevados daños ocasionados por este episodio climático extraordinario en el olivar ampurdanés, la causa real de la progresiva decadencia del olivar en el Empordà se inicia con los cambios en la estructura productiva de mediados del siglo pasado (encarecimiento de los costes de producción y de los salarios) a los que se añade, en las dos últimas décadas, la incidencia de la Política Agraria Comunitaria. El motivo de escoger Navata como caso de estudio se debe a la mayor disponibilidad de información documental existente en comparación a otros municipios ampurdaneses, tanto en relación a la incidencia que tuvo la helada de 1956 en el olivar como a las fuentes cartográficas, estadísticas y orales que permiten estudiar en detalle el proceso de declive del olivar en este municipio.

El artículo se estructura en seis apartados principales. En primer lugar, se describe la metodología y las fuentes de información utilizadas. En segundo lugar se presentan las características físicas y socioeconómicas del área de estudio, el municipio de Navata, así como las principales características climáticas y socioeconómicas del episodio de la helada de febrero de 1956 en el Alt Empordà. A continuación, se reconstruye el proceso de retroceso experimentado por el olivar en este municipio a partir de las fuentes cartográficas, estadísticas y orales. Por último se presentan y discuten los factores que, como resultado del estudio, se dilucidan como realmente determinantes para explicar este proceso de regresión del olivar en la comarca.

\section{Metodología y fuentes de información}

Tal y como se ha mencionado, han sido diversas las fuentes de información y metodologías utilizadas en este estudio de los cambios experimentados en el olivar en el municipio de Navata a partir de mediados del siglo XX y hasta la actualidad.

1. Recopilación bibliográfica de estudios realizados en materia de agricultura para el conjunto de la cuenca mediterránea, y con mayor concreción para Cataluña y el Alt Empordà, prestando especial atención al olivar. Entre los estudios consultados destacan las aportaciones de Loumou y Giourga (2003) y de Bonazzi (1997), mientras que la aproximación a la realidad del olivar en el Alt Empordà se llevó a cabo a través de los estudios de geógrafos regionales de la segunda mitad del siglo XX,

1 Datos facilitados por el Gabinete técnico del Departament d'Agricultura, Alimentació i Acció Rural de la Generalitat de Catalunya. 
como Compte (1963), Barbaza (1988) o Masgrau (1989), así como con los trabajos posteriores de Ribas y Saurí (2003), Serra (2002), Romero (2005), Serna y Hosta (2005) y Gifre $(2005,2006)$.

2. Recopilación, tratamiento y análisis de las diversas estadísticas agrarias disponibles (censos agrarios, actas sindicales, estadísticas agrarias municipales) para el área de estudio. Se ha de subrayar especialmente la consulta de datos estadísticos del Departament de Política Territorial i Obres Públiques y del Departament d'Agricultura, Alimentació i Acció Rural, ambos de la Generalitat de Catalunya, así como los censos agrarios del Instituto Nacional de Estadística (INE) y el Instituto de Estadística de Catalunya (IDESCAT). Además, se consultó diversa información disponible en el Arxiu Comarcal de l'Alt Empordà, el Institut d'Estudis Empordanesos y la Cambra Agrària Territorial de Girona.

3. Elaboración de una cartografía de los usos y cubiertas del suelo del municipio de Navata, mediante el SIG ARCGIS , para tres años de estudio (1957, 1970 y 2004) y a una escala de detalle (entre 1:7.500 y 1:5.000). El primer paso fue conseguir las fotografías aéreas correspondientes a la zona de estudio para los dos primeros años de análisis, 1957 y 1970, aportadas por el Centro Geográfico del Ejército. Posteriormente se realizó la ampliación y digitalización pertinente de ambas a escala 1:7.500. Para el año 2004 se utilizó el ortofotomapa digital a escala 1:5.000 facilitado por el Institut Cartogràfic de Catalunya. A continuación se procedió a la ortoreferenciación de las imágenes del 1957 y del 1970 mediante el soporte informático ERDAS Imagine 8.4, con el cual se pudo establecer una misma red de referencia para las tres imágenes analizadas. Finalmente se procedió a la fotointerpretación y digitalización de todo el material cartográfico reseñado mediante el SIG ArcView 9.1 y a partir de una leyenda categórica de doce ámbitos ${ }^{2}$, tres de ellos se centraron en precisar las características fisiognómicas y estructurales del olivar (olivar en campos, olivar en márgenes y olivar en abandono).

4. Realización de entrevistas de calado a agricultores que a mediados de la década de 1950-59 trabajaban la tierra y se dedicaban, ya fuese a jornada completa o como complemento de otras actividades, al cultivo del olivo en el municipio de Navata. En total se entrevistaron seis agricultores de edades comprendidas entre los setenta y ochenta años, todos ellos vinculados a la Hermandad Sindical de Labradores y Ganaderos de Navata.

5. Análisis y discusión de los resultados obtenidos. Determinación de los factores clave que explican el declive del olivar en el área de estudio.

\section{3. Área de estudio}

El municipio de Navata está situado en la comarca del Alt Empordà, en la vertiente más occidental del llamado Terraprim d'Empordà, espacio de transición entre la llanura ampurdanesa y la cubeta de Banyoles, en el territorio comprendido entre el curso medio del río Fluviá y el curso bajo del río Ter. Morfológicamente, el Terraprim d'Empordà está formado por una sucesión de relieves suaves y ondulados, de suelos poco profundos y altitudes inferiores a los 200 metros, donde se alternan espacios agrarios y forestales. Con una superficie de 18,5 km² y una población de 1.128 habitantes (IDESCAT, 2009), en Navata domina la agricultura de secano, centrada en el cultivo de cereales, trigo y alfalfa, y de

2 Las categorías definidas fueron: campos de olivar, olivar en márgenes, olivar en abandono, resto de cultivos, bosque, bosque de ribera, prados, espacios fluviales, suelo urbano, casas aisladas, red de comunicaciones y yermo. 
plantas forrajeras para la ganadería, como la cebada y la avena, entre otras. En referencia al cultivo del olivo, Navata sobresale en la variedad autóctona argudell, que produce un aceite dulce, suave y de elevada calidad. Es una variedad poco exigente con el terreno y en las técnicas de cultivo, perfectamente adaptada a las condiciones edafoclimáticas de la comarca del Alt Empordà, contexto exclusivo de dicha denominación. De maduración tardía y uniforme a partir de la primera semana de diciembre y hasta final del mismo mes, su fruto presenta una resistencia mediana a la caída, motivo de su buena adaptación a la cosecha mecanizada. Actualmente el municipio se encuentra dentro de la Denominació d'Orígen Protegida Oli de l'Empordà̉.

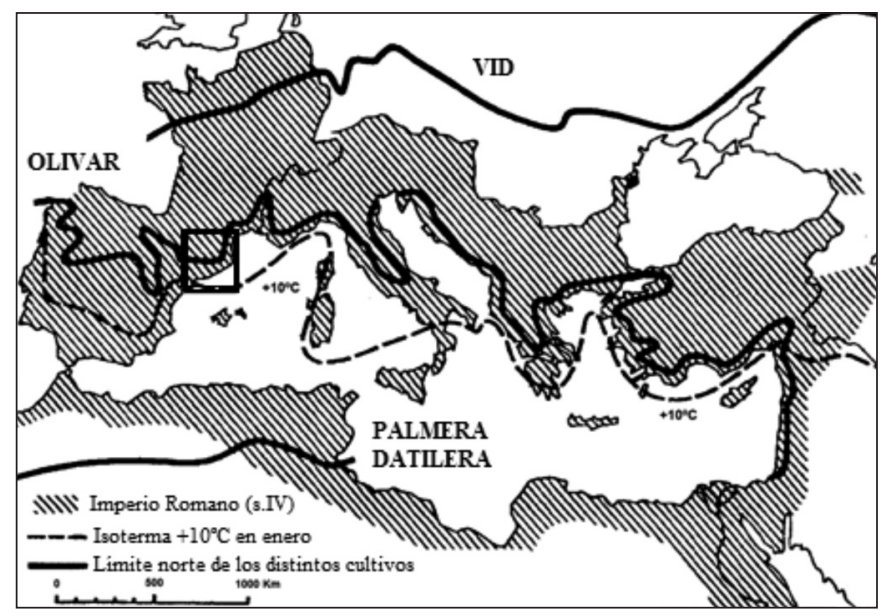

Figura 1. Localización de Cataluña en el límite septentrional del cultivo del olivo en el área mediterránea.

Fuente: Adaptado de Loumou y Giourga, 2003.

\section{1956: «l'any de la fred»}

\subsection{El fenómeno meteorológico: una siberiana de manual}

La situación meteorológica que se vivió durante el mes de febrero del 1956 consistió en una entrada de aire polar continental procedente directamente de Siberia. Pero ¿qué sucedió para que éstas masas de aire tan frío, que habitualmente no se mueven del norte de Europa y Asia, se descolgaran hacia Francia y la península Ibérica? La respuesta hay que buscarla en un potente anticiclón que se situó entre el Atlántico norte y Escandinavia durante unos cuántos días, mientras que una borrasca se instalaba en el Mediterráneo. Entre estas dos configuraciones de presión, se apostó el aire frío siberiano con bolsas de hasta quince grados bajo cero a mil quinientos metros de altura. Esto quiere decir temperaturas bajo cero en superfície durante buena parte del día (Riera, 2006). Como se puede ver en

3 Aprobada por la Orden AAR/200/2008, de 5 de mayo, del Departament d'Agricultura, Alimentació i Acció Rural de la Generalitat de Catalunya, actualmente en proceso de reconocimiento comunitario. Recientemente modificada por la ORDEN AAR/476/2010, de 1 de octubre (DOGC núm. 5734 - 14/10/2010). 
la figura 2, el aire frío abarcaba perfectamente todo la zona central y oriental de Europa, con acusada incidencia en países como Alemania, Francia, Suiza e Italia. Sin embargo, la ola de frío no provocó nevadas importantes en Cataluña porque el viento -que se mantuvo fuerte y persistente durante todos los días- resultó muy seco.
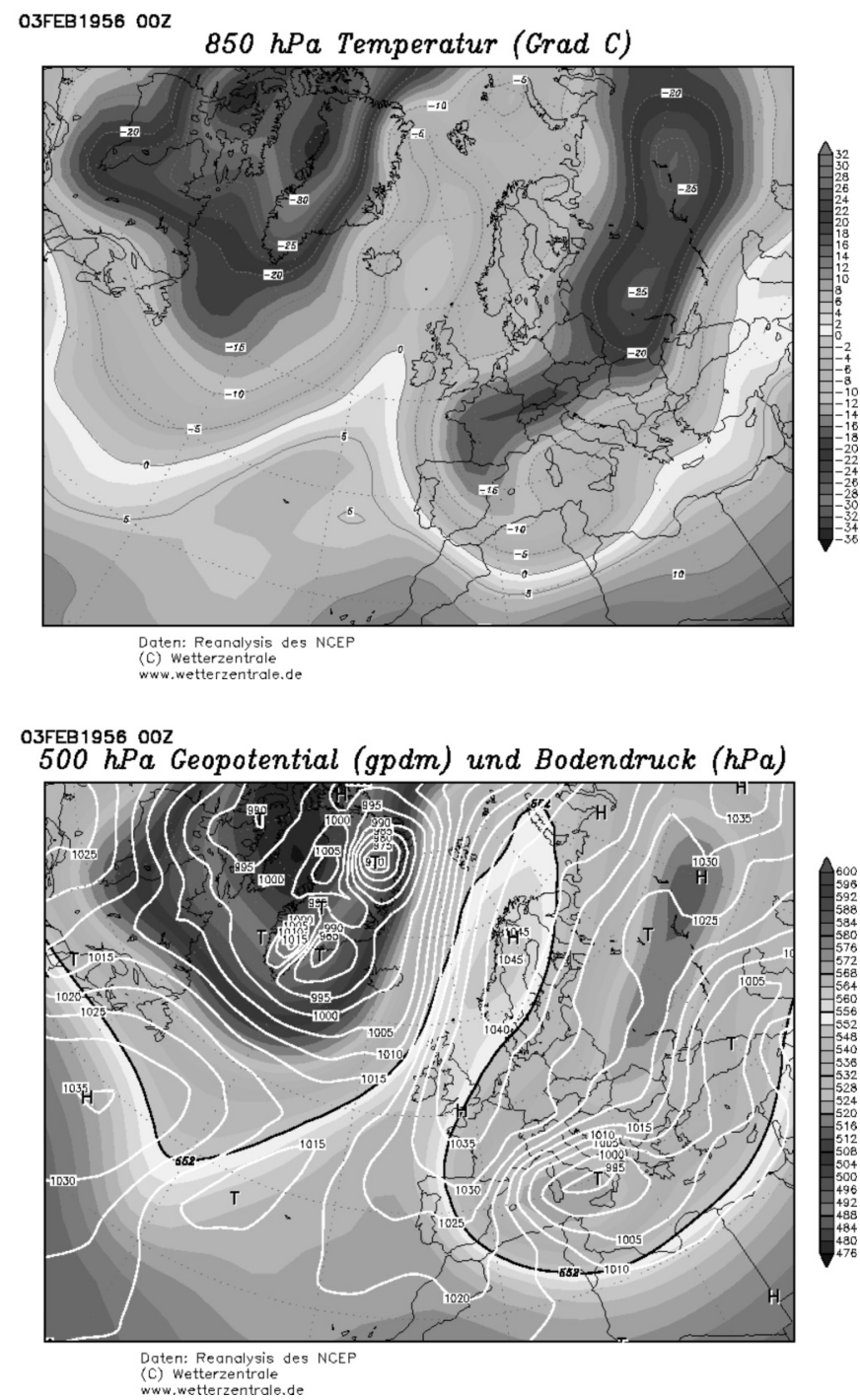

Figura 2. Mapas sinópticos del día 3 de febrero de 1956, a las 0 horas GMT. (Superior): Temperatura $\left({ }^{\circ} \mathrm{C}\right)$ en la superficie de $850 \mathrm{hPa}$, a unos 1500 metros sobre el nivel del mar. (Inferior): Presión a nivel del mar y altura geopotencial de la superficie de $500 \mathrm{hPa}$.

Fuente: http://www.wetter-zentrale.de/ 
La incidencia de olas de frío siberiano en Cataluña no es un hecho excepcional, pero suelen tener una duración muy corta. Entre los numerosos ejemplos son de fácil recuerdo reciente las olas de frío de enero del 1985, pero también las del año 1962 -con nevadas importantes en cotas bajas-y las de 1970, o las más recientes de los años 2001 ó 2005, todas ellas con temperaturas bajo cero en muchas zonas. Sin embargo, en aquel lejano febrero de 1956, el frío fue el de mayor intensidad y el de más larga duración de todo el siglo XX. Así, la situación vivida el mes de febrero de 1956 es recordada como uno de los episodios más gélidos del siglo XX en toda Europa (tabla 1).

Tabla 1

VALORES ESTADÍSTICOS DE ALGUNAS VARIABLES METEOROLÓGICAS EN GIRONA Y LOS CORRESPONDIENTES VALORES PARA EL MES DE FEBRERO DE 1956 Y EL MES DE ENERO DE 2005. FUENTE: CALBÓ, J. «EL CLIMA A LES COMARQUES DE GIRONA. L'ONADA DE FRED DE 1956», EN HOSTA, M. Y SERNA, E. (2005).

\begin{tabular}{|l|c|c|c|c|c|}
\cline { 2 - 6 } \multicolumn{1}{c|}{} & $\begin{array}{c}\text { Anual } \\
(1973-2000)\end{array}$ & $\begin{array}{c}\text { Febrero } \\
(1973-2000)\end{array}$ & $\begin{array}{c}\text { Febrero } \\
(1956)\end{array}$ & $\begin{array}{c}\text { Enero } \\
(1973-2000)\end{array}$ & $\begin{array}{c}\text { Enero } \\
(2005)\end{array}$ \\
\hline $\mathrm{T}^{\circ}$ media & $14,3^{\circ} \mathrm{C}$ & $8,0^{\circ} \mathrm{C}$ & $2,5^{\circ} \mathrm{C}$ & $6,9^{\circ} \mathrm{C}$ & $6,7^{\circ} \mathrm{C}$ \\
\hline $\mathrm{T}^{\circ}$ media de las máximas & $20,2^{\circ} \mathrm{C}$ & $13,9^{\circ} \mathrm{C}$ & $8,7^{\circ} \mathrm{C}$ & $12,8^{\circ} \mathrm{C}$ & $14,6^{\circ} \mathrm{C}$ \\
\hline $\mathrm{T}^{\circ}$ media de las mínimas & $8,4^{\circ} \mathrm{C}$ & $2,0^{\circ} \mathrm{C}$ & $-3,7^{\circ} \mathrm{C}$ & $1,0{ }^{\circ} \mathrm{C}$ & $-1,2^{\circ} \mathrm{C}$ \\
\hline $\mathrm{T}^{\circ}$ mínima absoluta & $-13,0^{\circ} \mathrm{C}$ & $-10,5^{\circ} \mathrm{C}$ & $-10,5^{\circ} \mathrm{C}$ & $-13,0{ }^{\circ} \mathrm{C}$ & $-9,5^{\circ} \mathrm{C}$ \\
$(12 / 1 / 1914)$ & $(3 / 2 / 1956)$ & $($ día 3) & $(12 / 1 / 1914)$ & $($ día 27$)$ \\
\hline Días con hielo & 44 & 9 & 24 & 14 & 18 \\
\hline Días con nieve en tierra & 1 & 0 & 4 & 0 & 0 \\
\hline
\end{tabular}

\subsection{Los detalles de la ola de frío: el Alt Empordà y el olivar}

El frío que «mató los olivos» empezó a penetrar en Cataluña la noche del 1 de febrero y, durante el día 2, se extendió rápidamente por toda la Península. En el observatorio meteorológico de Girona se registró, el día 6, una temperatura mínima de $-1{ }^{\circ} \mathrm{C}$, cuando en las fechas precedentes había bajado hasta los $-9^{\circ} \mathrm{C}$ o incluso hasta los $-10,5^{\circ} \mathrm{C}$ el día 3 (record de temperatura mínima del siglo $\mathrm{XX}$ en este observatorio). Unas temperaturas que, lejos de aumentar, permanecerían alrededor de $\operatorname{los}-10{ }^{\circ} \mathrm{C}$ durante los días sucesivos. El frío intenso duraría todavía hasta el día 22, cuando una masa de aire cálido desplazó finalmente el aire siberiano.

En la comarca del Alt Empordà se llegó a temperaturas de hasta $-15^{\circ} \mathrm{C}$ (en el Observatori de Figueres las mínimas absolutas llegaron a los $-9{ }^{\circ} \mathrm{C}$, mientras, la temperatura mediana del mes fue de $3,05{ }^{\circ} \mathrm{C}$ y la media de las temperaturas mínimas de $-2,2{ }^{\circ} \mathrm{C}$ ). Mientras que la media de días con helada en el período 1951-1962 fue de 31 días, en el año 1956 fue de 54 días (Gifre, 2006a; Riera, 2006).

Las peores consecuencias de este fenómeno meteorológico extremo las sufrió la agricultura: aparte de los olivos muertos, también se helaron los algarrobos, muchos árboles 
frutales y, naturalmente, la poca huerta que había plantada en aquel mes. Respecto a los cereales (Gifre, 2006a), no todos sufrieron las consecuencias del frío de la misma manera, pues dependió del periodo de crecimiento vegetativo en qué estos se encontraran. «En cambio, los efectos sobre los olivos fueron más generales», comenta Gifre (2006a: 454), que destaca que los olivos más afectados fueron aquellos que ya habían sido podados en enero después de recoger las aceitunas. «Las bajas temperaturas, con heladas intensas y los fuertes vientos de tramuntana provocaron que se rompieran ramas e incluso que estallaran cepas enteras», apunta Gifre (2005: 35).

Hasta mediados del pasado siglo, el olivar dominaba ampliamente el paisaje agrario del Alt Empordà, desde las Alberas, en el sector del municipio de Espolla, hasta los relieves de Garrigàs y Arenys d'Empordà, o más hacia el sur, ya en la comarca del Baix Empordà. Pero a partir de 1956 este paisaje cambia radicalmente (Iglesias, 2006: 21).

Así, pasado el frío intenso se empezaron a evaluar los daños con el fin de solicitar ayudas oficiales que redujeran los efectos negativos sobre el campo. Muchos campesinos querían arrancar los olivos muertos para utilizar los campos para otros cultivos más rentables, pero estos árboles estaban protegidos por el decreto autárquico de 1946. Una vez valorados los daños considerables en los olivares y a petición de muchos ayuntamientos, el estado permitió arrancarlos. En el Ampurdán, en palabras del historiador Pere Gifre (2006a: 449), el arranque de los olivos «se tiene que enmarcar en el proceso más amplio de crisis de la agricultura tradicional, en la cual el frío de febrero de 1956 supone el punto irreversible de inflexión y la motorización de los trabajos agrarios».

Las autoridades locales actuaron con premura para conseguir la declaración de calamidad extraordinaria, es decir, argumentaron la afectación de más del 25\% de los cultivos para así obtener la exención de la contribución rústica. Según Gifre (2006a: 449-464) es factible pensar que las evaluaciones de los daños, al tratarse de documentos administrativos que debían probar la confirmación de calamidad extraordinaria, fuesen exageradas. Del 60 al 95\% de los cultivos debieron quedar afectados, aunque también debe tenerse en cuenta la suavidad térmica del mes de enero precedente, que hacía prever el fin del invierno. Este factor contribuyó a que el olivo avanzase su ciclo de floración en prácticamente dos meses por lo que los daños de la helada se agudizaron.

A partir del mes de septiembre del mismo año, los propietarios de olivos muertos o con daños solicitaban autorización para la poda y corta de los olivos de su propiedad, de acuerdo con las instrucciones dadas por la Jefatura Agronómica provincial en escrito de 5 de septiembre. El proceso será rápido y la Dirección General de Agricultura dará luz verde a la petición, mediante la reglamentación facilitada a las Hermandades de Labradores y la Jefatura Agronómica, en una orden de 17 de octubre de 1956 (BOE, 299 de 25 de octubre de 1956: 6.783), según la cual se podían arrancar los olivos, sin exigir la previa replantación, en el caso de que su productividad fuese inferior al $25 \%$ de la que tenían antes de la ola de frío. La disposición establecía, también, un plazo para efectuar dicho arranque, el 30 de abril de $1957^{4}$. La orden gubernamental pretendía resolver la limitación que había impuesto el decreto autárquico de 1946 que prohibía, entre otros, el arranque de olivos por ser «especies arbóreas muy importantes para la economía nacional». Sin embargo, los plazos de arranque se alargaron. No todos los olivos se arrancaron de inmediato, algunos fueron coronados, con la esperanza que volvieran a brotar ${ }^{5}$. Muchos de los olivos, además, se iban secando. Una circular de la Cámara Agraria de Gerona, resultado del traslado desde

4 Dado que la fotografía aérea del 1957 se realizó en el mes de mayo, el proceso de arranque de los olivos afectados probablemente ya había empezado.

5 Los agricultores entrevistados hablan de un período de dos años de paréntesis, a la espera de que el olivo mejorase o muriera. 
la Dirección General de Agricultura en fecha de 9 de junio de 1960, estableció como plazo improrrogable para el arranque de olivo, con producción inferior al $25 \%$ y sin necesidad de replantación, el 31 de diciembre de 1961. Así pues, en poco menos de cinco años, de 1956 a 1961, tuvo lugar un considerable proceso de arranque del olivar. Los agricultores propietarios obtuvieron de esta forma unos ingresos que debían compensar la pérdida de la cosecha de 1956, que a priori debería haber sido buena dado que la del año anterior había sido de traspaso o de contra-añada.

Se organizaron cuadrillas de agricultores y jornaleros que se hicieron cargo del arranque con métodos manuales, picos, azadas, palas y palancas de hierro para tumbar los olivos, así como masas y cuñas para hendirlos. Esta actividad dio trabajo durante cinco años a un buen nombre de pequeños agricultores, jornaleros y negociantes. Una vez terminada la actividad, los jornales fueron reduciéndose progresivamente hasta que las almazaras de aceite empezaron a reducir su producción, antes de desaparecer.

Las estadísticas oficiales españolas no presentan cambios significativos derivados del arranque de olivo. La superficie se mantiene prácticamente constante entre los años cincuenta y sesenta, del mismo modo que la producción de aceite tampoco protagoniza cambios especialmente significativos. La única excepción es la provincia de Girona, y dentro de ésta, el Ampurdán como zona de mayor afectación. Aquí el proceso de arranque fue muy rápido. En cinco años, para un conjunto de dieciséis municipios del terraprim occidental ampurdanés, el $62 \%$ de la superficie ocupada por olivar desapareció. Lento fue el arranque en Avinyonet de Puigventós o Figueres, progresivo en Sant Mori, Saus-Camallera y Vilaür, y espectacular en Pontós y muy especialmente, en Navata. En este municipio, la afectación del frío de 1956 tuvo especial incidencia en los olivos ya medio abandonados pero también en aquellos olivos centenarios que rodeaban el núcleo urbano. Así mismo, se aprovechó el arranque para propiciar el auge de los cereales, sobre todo de trigo y cebada, pero también de plantas forrajeras, como el centeno o la veza. Ciertamente, a este factor responde la radicalidad del cambio paisajístico, pero cabe tener en cuenta que, con anterioridad a la helada, el cultivo del olivar ya se encontraba en proceso de abandono dada su baja rentabilidad frente a los cereales.

\section{La decadencia del olivar en cifras}

A partir del episodio de la helada de febrero de 1956 el olivar experimenta un retroceso imparable hasta llegar a su práctica desparación a las puertas del siglo XXI. Las figuras 3 y 4 y la tabla 2 permiten reconstruir detalladamente este proceso. El mapa de usos y cubiertas del suelo del año 1957 muestra la significativa presencia del olivar en Navata a mediados del siglo pasado, con una superficie de 203,2 hectáreas (el 10,9\% de la superficie municipal), 151,5 de las cuales en forma de campos de olivos (74,5\%), 45,1 en olivos en márgenes $(22,3 \%)$ y 6,6 en forma de olivares abandonados $(3,2 \%)$. El resto de cultivos ocupan 941,9 hectáreas $(50,48 \%$ del total de la superficie municipal), especialmente dedicados al cultivo de la alfalfa y plantas forrajeras. La suma del bosque y los prados asciende a 604,4 hectáreas $(32,4 \%$ del total municipal) y la superficie urbanizada constituye las 14,3 hectáreas restantes $(0,7 \%$ del total municipal).

El mapa de 1970 radiografía el significativo descenso del olivar, que pasa a ocupar apenas 39,2 hectáreas (2,1\% del total municipal), 37,4 de las cuales en forma de campos de olivos (95\%), 1,23 en olivos en abandono (3,3\%) y 0,59 en olivos en márgenes $(1,7 \%)$. La pérdida de protagonismo del olivar va en beneficio de los otros tipos de cultivos, que aumentan su presencia hasta las $1.101,7$ hectáreas (59,05\% del total municipal), resaltando el incremento del trigo y las plantas forrajeras. Por su parte, el conjunto de bosque y prados 


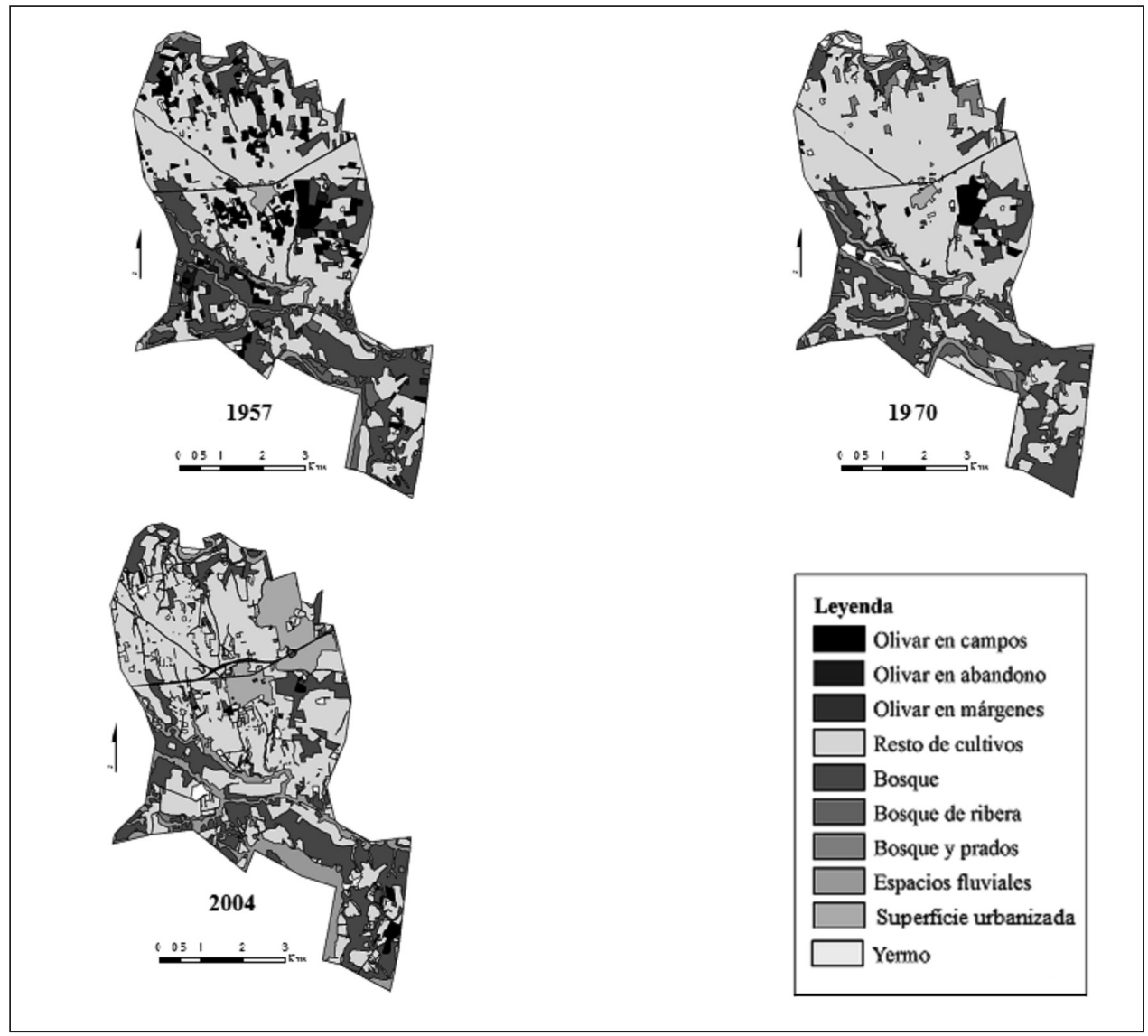

Figura 3. Evolución de los usos y cubiertas del suelo del municipio de Navata (años 1957, 1970 y 2004).

Fuente: Fotografía aérea de 1957 y 1970. Ortofotomapa de 2004. Elaboración propia.

se mantiene entorno a un tercio de la extensión del municipio, con 610,2 hectáreas (32,7\% del total municipal), mientras la superficie urbanizada se mantiene prácticamente igual. Los resultados obtenidos para el año 2004 ponen de manifiesto, más si cabe, el descenso del olivar, que ocupa tan solo 19,4 hectáreas (un testimonial 1\% del total municipal), la práctica totalidad de ellas mediante campos de olivos, pues el olivar en márgenes ha desaparecido casi de manera absoluta. Tanto el resto de cultivos (989,76 hectáreas, 53,04\% del total municipal) como la suma de bosque y prados (498,82 hectáreas, 26,74\% del total municipal) pierden peso a favor de la superficie urbanizada, que aumenta hasta las 141,39 hectáreas (7,6\% del total municipal), resultado tanto del crecimiento entorno al núcleo urbano como del auge en el sector de Torremirona, con la construcción del complejo residencial y recreativo de Torremirona Golf en el año 1993.

Las fuentes estadísticas disponibles también atestiguan este rápido retroceso (Tabla 2) si bien los resultados estadísticos oficiales difieren substancialmente de los cartográficos que se han obtenido para los tres años de referencia (1956,1970 y 2004). Estos últimos presentan 

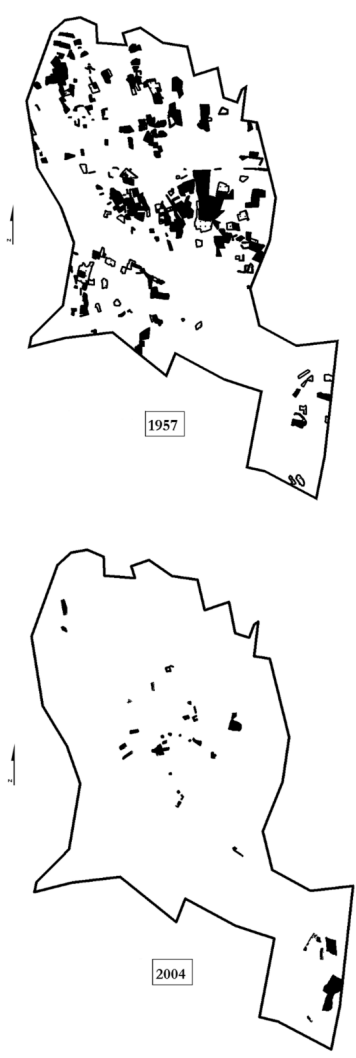

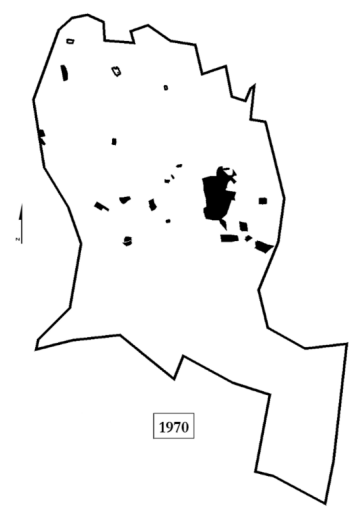

\section{Campos de olivar \\ Olivar en abandono \\ Z Olivar en márgenes}

FIgURA 4. Evolución del olivar en el municipio de Navata (años 1957, 1970 y 2004). Fuente: Fotografía aérea de 1957 y 1970. Ortofotomapa de 2004. Elaboración propia.

una mayor superficie de olivar si se comparan con las estadísticas y los estudios previos disponibles. Su explicación se debe buscar, en primer lugar, en las limitaciones propias de las fuentes documentales consultadas, algunas de las cuales, como los censos agrarios, son de carácter estructural, de tal modo que enfocan los resultados sobre las explotaciones agrarias y no sobre las superficies de las mismas, aspecto que propicia desviaciones por exceso o por defecto ${ }^{6}$ de la superficie real afectada. Por lo que respecta a las actas sindicales, estas no siempre pueden plasmar con suficiente exactitud el balance superficial de los años consultados, de manera que en algunos casos, para un mismo año existen datos superficiales distintos. Por otro lado, debe aceptarse el propio margen de error en la fotointerpretación de las imágenes aéreas de 1957 y de 1970, atribuible por la dificultad de discernir, en algunos momentos, entre el olivar en abandono y la superficie boscosa. Si se toman en consideración las limitaciones anteriores, los resultados en términos relativos revelan una pérdida del orden del 90\% del olivar presente en el año 1957.

6 Como ejemplo, el Censo agrario de España del año 1972 recoje para el municipio de Navata una superfície geográfica de 2.316 hectáreas, mientras la superfície censada es de tan solo 2.085 hectáreas. 
Tabla 2

EVOLUCIÓN DEL OLIVAR A PARTIR DE DISTINTAS FUENTES ESTADÍSTICAS (1946-2004)

\begin{tabular}{|l|c|c|}
\hline \multicolumn{1}{|c|}{ Año } & $\begin{array}{c}\text { Superficie en ha. } \\
\text { (según estadísticas agrarias) }\end{array}$ & Superficie en ha. (según cartografía) \\
\hline 1946 & $180^{(* * *)}$ & \\
\hline 1953 & $195^{(* * *)}$ & \\
\hline 1955 & $176^{(* *)}$ & \\
\hline 1956 & $168^{(* *)}$ & \\
\hline 1957 & & \\
\hline 1958 & $48^{(* * *)}$ & \\
\hline $1959-62$ & $0^{(* * *)}$ & \\
\hline 1962 & $54^{(*)}$ & \\
\hline $1963-69$ & $0^{(* * *)}$ & \\
\hline 1970 & & 39,2 \\
\hline 1972 & $20^{(*)}$ & \\
\hline $1972-77$ & $0^{(* * *)}$ & \\
\hline 1981 & $0^{(* *)}$ & \\
\hline 1982 & $1^{(*)}$ & \\
\hline 1989 & $0^{(*)}$ & \\
\hline $1991 / 94$ & $3^{(* *)}$ & \\
\hline 1996 & $1,26^{(* *)}$ & \\
\hline 1999 & $5^{(*)}$ & \\
\hline 2004 & $5^{(* *)}$ & \\
\hline
\end{tabular}

(*) Según censos agrarios

(**) Según DAR y MAPA

(***) Según las Actas sindicales de la Hermandad Sindical de Labradores y Ganaderos de Navata (1944-1977).

Fuente: Censos agrarios 1962, 1972, 1982, 1989, 1999; DAR, MAPA y Actas sindicales de la Hermandad Sindical de Labradores y Ganaderos de Navata (1944-1977).

\section{Los factores del cambio: más allá de la ola de frío}

\subsection{La estructura productiva agraria}

Si bien la helada de 1956 comportó cuantiosos daños en el olivar y marcó, en la memoria popular, el punto de inicio del radical cambio paisajístico que se traduce en su práctica desaparición de la plana altoampurdanesa, los verdaderos factores de este cambio cabe buscarlos, al igual que sucede en muchas otros sectores del litoral peninsular, en las transformaciones que sufre la estructura productiva agraria a partir de mediados del siglo pasado. Enmarcada en un amplio proceso de crisis de la agricultura tradicional, la estructura productiva agraria es incapaz de hacer frente al encarecimiento que afecta a los costes de producción y de salarios (los jornales vinculados a la cosecha y a la poda, especialmente). 
Cabe añadir aquí una subida del precio del trigo después del fin del racionamiento del pan en 1951, que hace preveer buenas expectativas para este sector.

La crisis del olivar tradicional se produce, definitivamente, a partir de la década de 1960, cuando se empiezan a generalizar las tendencias de mecanización y fertilización artificiales (Zamora, 1986). El olivo había sido hasta entonces un cultivo con pocas exigencias agronómicas que lo hacían compatible con otras producciones, pero a partir de este momento el olivar intensivo exigirá mucha mano de obra y una alta productividad para ser comercialmente competitivo (Zambrana, 1987). Sin embargo, los costes de producción no disminuyeron y los rendimientos tampoco aumentaron, de tal forma que se hizo necesaria una dependencia energética (con derivados del petróleo para la maquinaria) y la aplicación de abonos sintéticos para intentar recuperar el liderazgo del sector. De aquí que fuese la inmediatez de la ganancia lo que explicó, en parte, el arranque masivo del olivar así como el auge de los cereales, especialmente en el caso del trigo y los forrajes; estos últimos, poco a poco, irían ganando relevancia en la economía agraria ampurdanesa (Serna y Testart, 2005).

Se ha de recordar aquí como el principal estudio económico sobre el sector oleícola en España en la década de los años setenta, realizado por Agustín López Ontiveros (1978), detectó dos grandes problemas del sector olivarero. El olivar de los años cincuenta, cultivado de forma manual, con salarios bajos y siendo el aceite de oliva el único presente en el mercado nacional, ya derivó en los años setenta hacia la competencia con el aceite de girasol, el de soja o el de cacahuete. López Ontiveros alude a dos causas principales explicativas de la crisis del olivar. Por un lado, los elevados costes de recolección que redundan en las rentas y la competitividad del aceite de oliva por la vía de los precios, o dicho de otra manera, por la pérdida de paridad entre el precio percibido en el mercado y el precio pagado en origen por los costes, todo ello debido a la competencia de los otros aceites de menor precio. Por otro, la existencia de un oligopolio en el sector oleícola (sector transformador-envasador) que coexistía con una agricultura (sector productor) en competencia perfecta. Se trataba de dos sectores que poseían grandes diferencias en cuanto a la organización sectorial, la capacidad de gestión o el poder de mercado, por ejemplo, que dificultaban que las organizaciones de agricultores o el sector productor en si mismo pudieran arrebatar cuota de mercado al sector transformador (de características mayoristas y en manos de capital extranjero), dejando como vía de escape el acceso directo al canal comercial para obtener mayores rentas.

\subsection{La Política Agraria Común y la Organización Común de Mercado de las Oleaginosas}

A mediados de la década de 1980, con la entrada de España en la entonces Comunidad Económica Europea (CEE), un tercer factor irrumpirá en escena en la dinámica del olivar en el municipio de Navata y, por extensión, en la comarca del Alt Empordà: la Política Agraria Común (PAC) y sus mecanismos de regulación con el sector del aceite: la Organización Común de Mercado de las Oleaginosas (OCMo).

La política comunitaria de las oleaginosas tuvo su origen en el Reglamento del Consejo Europeo de 1966 por el cual se estableció una organización común de mercado dentro del sector de las materias grasas ${ }^{7}$. Dentro de ella el aceite de oliva y sus derivados constaban explícitamente en la categoría «C»del artículo 1 , así como la categoría «D» del mismo trataría el fruto del olivo, las aceitunas, en todos sus formas.

Los objetivos de dicho reglamento eran escasos pero claros: asegurar la demanda del mercado europeo, fuertemente importador en ese momento; promover el uso y el consumo preferencial del aceite de oliva por encima de otros aceites importados; y garantizar unos

7 Reglamento 136/66/CEE del Consejo, de 22 de septiembre de 1966. 
ingresos adecuados para el productor. De ahí la necesidad de incidir ante los precios del mercado y ante los índices de producción de la mano de subvenciones (Vázquez, 2009). En el caso de Navata (y por extensión el Alt Empordà), con una dedicación al sector del aceite constituido mayoritariamente de pequeños productores, las disposiciones relativas a las ayudas a la producción que priorizaban las economías locales, tuvieron su repercusión directa en la continuidad, aunque mínima, del cultivo del olivo.

En 1998 se hizo preciso impulsar una nueva reforma de la política común que respondiera al nuevo contexto: tendencia a los excedentes estructurales promulgados por la extensión de la superficie productiva, fraudulencia en el otorgamiento de subvenciones y falta de mecanismos que abogasen por la mejora de la calidad productiva. Ante tal situación la Comisión propuso dos líneas modificatorias: una de mejora del sistema actual y otra mucho más precisa de ayuda directa al olivo. Así es como la reforma de 1998 recogió varias modificaciones:

a. Se suprimió la referencia de los precios;

b. Se suspendieron los mecanismos de intervención pero se mantuvo la posibilidad de ayuda comunitaria al almacenamiento privado;

c. Se eliminaron las subvenciones al consumo;

d. Se aplicó a todos los productores de aceite de oliva una ayuda determinada en base a su producción real, mientras que la ayuda a los pequeños productores se calculó en base a una producción convencional estimada;

e. Se estableció que la producción de los olivares plantados después del 1 de mayo de 1998 no sería receptora de ayudas.

Esta reforma de 1998 explica, en buena parte, el auge contenido del olivo en el municipio de Navata durante los años venideros. Así, se entiende que es la ayuda al pequeño productor -aquel que ha mantenido el cultivo del olivo a lo largo de los años con carácter subsistente-, la medida que, a grandes rasgos, ha promovido el apego continuado de dicho cultivo al territorio (ADE, 2002; Cejudo y Maroto, 1993; García Delgado y García Grande, 2005; Lambarra, 2009).

\section{Conclusiones}

La pérdida del paisaje de olivar de mediados del siglo XX, característico de la cuenca mediterránea y de municipios alto-ampurdaneses como Navata, es un claro indicador de la transformación del marco agrario tradicional hacia otro más mecanizado e industrial. En el caso de estudio, los factores de esta transformación, la helada de 1956, la estructura productiva agraria y el impacto de la Política Agraria Común de la mano de la Organización Comuna de Mercado de las Oleaginosas, ayudan a entender el lugar testimonial que ocupa actualmente el olivar en relación al gran protagonismo de antaño. A lo largo del período analizado (1957-2004), y a excepción de la vid y el olivar, el resto de cultivos han incrementado su presencia, con el trigo, la cebada y las plantas forrajeras dominando el paisaje agrario del municipio de Navata.

Sin embargo, los valores económicos, ecológicos y culturales del olivar, plantean hoy en día la necesidad de recuperar el carácter distintivo de su paisaje, que aporta calidad productiva y equilibrio ecosistémico a la comarca. En este sentido, los distintos Reglamentos europeos ${ }^{8}$ desde 1998 y en materia de cultivos oleaginosos, apuestan por

8 Reglamento (CE) n ${ }^{\circ}$ 1513/2001 del Consejo, de 23 de julio de 2001. Reglamento (CE) $\mathrm{n}^{\circ} 865 / 2004$ del Consejo, de 29 de abril de 2004. Reglamento (CE) n 865/2004 del Consejo, de 29 de abril de 2004. 
dar un nuevo impulso al sector. Este impulso pasa no sólo al fortalecimiento de la competitividad productiva, sino que incide de forma clara en la promoción de una agricultura que respete el medio ambiente y potencie el desarrollo rural (especialmente en lo que se refiere a la mejora del tratamiento productivo de zonas desfavorecidas), también en el fortalecimiento de la seguridad alimentaria, y en la mejora de la calidad y la protección de las indicaciones geográficas. Es en éste contexto donde la recuperación y estímulo de una variedad de aceite como la argudell (u otras representativas del sector como la corivell y la arbequina) puede considerarse, para la comarca del Alt Empordà i el municipio de Navata, como una buena forma de diversificar el mercado apostando por un producto de referencia local. Supone además una medida para mejorar la valoración de la variedad aceitosa reconociéndola como una indicación geográfica de referencia y, por qué no, como una premisa para acrecentar el desarrollo de un territorio que todavía mantiene un marcado carácter rural.

\section{Bibliografía}

ADE (2002): Evaluation des impacts des principales mesures de l'OCM dans le secteur de l'huile d'olive, Volume 1 - Rapport final. Accesible en www.ade.be.

ANTA, JL. et al. (2005): La cultura del olivo. Ecología, economía, sociedad. Universidad de Jaén, Jaén.

BARBAZA, Y. (1988): El paisatge humà de la Costa Brava. Edicions 62, Barcelona. Volum I, pp. 337, 366-369. Volum II, pp. 28-29, 119-120.

BARRANCO, D. et al (2008): El cultivo del olivo. Madrid: Ediciones Mundi-Prensa y Junta de Andalucía, $6^{\text {a }}$ edición, 846 pp.

BOLENS, L. (1996): «Riquezas de la tierra andaluza y primacía del aceite de oliva en la sociedad y la civilización de al-Andalus (siglos X-XVI)», en Agricultura y sociedad, n 80-81, pp. 181.

BONAZZI, M. (1997): «Políticas euromediterráneas y aceite de oliva: ¿competencia o reparto del trabajo?» en Olivae, $\mathrm{n}^{\circ} 65$, pp. 16-20.

CEJUDO, E. y MAROTO, J. (1993): «Pasado, presente y futuro de la OCM del aceite de oliva», en Cuadernos Geográficos, no 29 , pp. 85-117.

CIVANTOS, L. (1995): «Evolución de la superficie plantada de olivos y de la producción de aceite de oliva en España», en Olivae, n ${ }^{\circ}$ 59, pp. 18-21.

COMPTE, A. (1963): «El Alto Ampurdán», en Pirineos, nº 67-74, pp. 43-45.

DAR (2008): Olivera. Estadístiques bàsiques. Departament d'Agricultura, Alimentació i Acció Rural. Gabinet Tècnic. Disponible en http://www20.gencat.cat/docs/DAR/DE_Departament/DE02_Dades\%20i\%20estadistiques/05\%20Fitxes\%20sectorials/Fitxers\%20estatics/ OLIVERA(web)08_09_09.pdf

FAOSTAT (2008): Anuario Estadístico de la FAO 2007-2008. Disponible en http://www.fao.org/economic/ess/publicaciones-estudios/statistical-yearbook/anuario-estadistico-de-la-fao-2007-2008/ es/

FLESKENS, L. et al. (2009): «A conceptual framework for the assessment of multiple functions of agro-ecosystems: A case study of Trás-os-Montes olive groves», en Journal of Rural Studies, $\mathrm{n}^{\circ}$ 25, pp. 141-155.

FORTUNY, J. (2002): Metodología del análisis sectorial en el sistema agroalimentario aplicada al subsector oleícola catalán. Evaluación de la competitividad, el progreso tecnológico y la eficiencia económica empresarial. Tesis doctoral. Edición: TDX.

GARCÍA DELGADO, J. y GARCÍA GRANDE, M. (Eds.) (2005): Política agrària comuna: balanç i perspectives. Caixa d'estalvis i pensions de Barcelona, Servei d'Estudis. Barcelona, 189 pp.

GIFRE, P. (2005): «El fred de 1956. Una visió histórica», en 1956. L'any de la fred. L'Observatori Meteorològic de Girona. Figueres, pp. 14-20.

GIFRE, P. (2006a): «La gran transformació del paisatge rural empordanès. El terraprim occidental (1950-1980). Tot valorant la incidència del fred de 1956», en El paisatge, element vertebrador de la identitat empordanesa, vol. II. Figueres, pp. 449-464. 
GIFRE, P. (2006b): «Un episodi de la plantada de vinyes i oliveres a l'Empordà (1773-1777) explicat en primera persona», en El paisatge, element vertebrador de la identitat empordanesa, vol.II. Figueres, pp. 375-382.

HOSTA, M. y SERNA, E. (coord.) (2005): 1956. L'any de la fred. L'Observatori Meteorològic de Girona. Arxiu Històric de Girona i Arxiu Comarcal de l'Alt Empordà. 47 pp.

IDESCAT (2009): Fitxes municipals 2009. Disponible en http://www.idescat.cat/territ/BasicTerr?TC $=3 \& \mathrm{~V} 0=1 \& \mathrm{PDF}=\mathrm{FALSE} \& \mathrm{~V} 1=17111 \& \mathrm{VOK}=\mathrm{Confirmar}$

IGLESIAS, N. (2006): «1956-2006: mig segle de l'any que la fred va matar les oliveres», en Revista de Girona, $\mathrm{n}^{\circ} 237$, pp. 20-23.

IOC (2009): Chiffres clés du marché mondial des olives de table. Données adoptées en $97^{\circ}$ session du COI (Madrid, Espagne, 16-20 novembre 2009). Disponible en http://www.internationaloliveoil. org/downloads/Baltable07.pdf

LAMBARRA, F. et al., (2009): «The impact of the 1999 CAP reforms on the efficiency of the COP sector in Spain», en Agricultural Economics, vol. 40, pp. 355-364.

LÓPEZ ONTIVEROS, A. (1978): El sector oleícola y el olivar: oligopolio y coste de recolección, Serie Estudios, Madrid: Ministerio de Agricultura, $216 \mathrm{pp}$.

LOUMOU, A. y GIOURGA, C. (2003): «Olive groves: The life and identity of the Mediterranean», en Agriculture and Human Values, ${ }^{\circ}$ 20, pp. 87-95.

MARM (2008): Anuario de Estadística 2008. Madrid: Subdirección General de Estadística.

MASGRAU, R. (1989): Alt Empordà: paisatge, població, economia, història, art, tradicions. Ediciones Barcanova, Barcelona, 63 pp.

MATÉ, V. et al., (2004): «El olivar en España», en Dossier Oleo. Madrid, pp. 11-24.

MERCACEI, A. (1998): «El olivar de Cataluña», en Mercacei Magazine Mercado Aceitero, $\mathrm{n}^{\circ} 17$.

RIBAS, A. y SAURÍ, D. (2003): «Canvis socioambientals a l'Alt Empordà (1950-2000): natura i història en l'evolució recent del paisatge altempordanès» en Els canvis demogràfics, Girona.

RIBAS, A. et al. (2006): «L'evolució recent del paisatge de l'Alt Empordà a partir de l'anàlisi en els canvis d'usos i cobertes del sòl (1950-2000)», en El paisatge, element vertebrador de la identitat empordanesa, vol. I. Figueres, pp. 51-71.

RIERA, M. (2006): «L'any de la fred», en Presència, n 1770, pp. 17-20.

ROMERO, M. (2005): Cambios en la estructura del paisaje del Alt Empordà en el período 19572001. Tesis doctoral. Edición: TDX.

SABATÉ, P. y COLOM, A. (1994): Una aproximación al sector del aceite de oliva. Desde Lleida hasta la UE y los países del área mediterránea. Anuario de la Fundación de Lleida. Lleida, pp. 323-347.

SERNA, E. y TESTART, A. (2005): Un segle d'associacionisme agrari a Navata. Ajuntament de Navata, pp. 17-18, 85-172, 210.

SERRA, P. (2002): Dinàmiques del paisatge agrari a l'Alt Empordà (1977-1997): Una anàlisi a partir de la Teledetecció i dels Sistemes d'Informació Geogràfica. Tesis Doctoral, Edición: TDX.

VÁZQUEZ, C. (2009): «La incidencia de las reformas de la PAC en el olivar», en Notícias de la Unión Europea, n ${ }^{\circ}$ 293, pp. 181-191.

ZAMBRANA, JF. (1987): Crisis y modernización del olivar español: 1870-1930. Serie Estudios. Ministerio de Agricultura, Pesca y Alimentación, Secretaría General Técnica. Madrid, 472 pp.

ZAMORA, G. (1986): «Actualidad, ocupación y productividad agraria en España: un análisis de la población y el empleo», en Revista de Estudios Agro-sociales, nº 137 Extra septiembre, pp. 379-417.

\section{Agradecimientos}

Nuestro más sincero agradecimiento a Pere Gifre, Miquel Riera y Erika Serna por la información facilitada sobre la afectación de la helada de 1956 en la comarca del Alt Empordà. También a los agricultores de Navata entrevistados, Francisco Bret, Pere Cortal, Josep Espidulé, Pere Miquel y Josep Vallmajó, por haber hecho posible conocer sus propias vivencias en torno a los efectos de la helada y los cambios experimentados por el olivar desde mediados de siglo pasado y hasta hoy en día. 